Supporting information for

\title{
Particulate oxynitride photoanodes assembled with transparent electron-collecting oxide nanorod arrays
}

Feng-Qiang Xiong, ${ }^{*},+$ Beibei Dong, ${ }^{\ddagger}$ and Shuwen Yü

†School of Chemistry, Biology and Material Science, East China University of

Technology, Nanchang, Jiangxi, 330013, China. E-mail:

xiongfengqiang@ecut.edu.cn

‡Dalian National Laboratory for Clean Energy, Dalian Institute of Chemical

Physics, Chinese Academy of Sciences, Dalian, Liaoning, 116023, China 


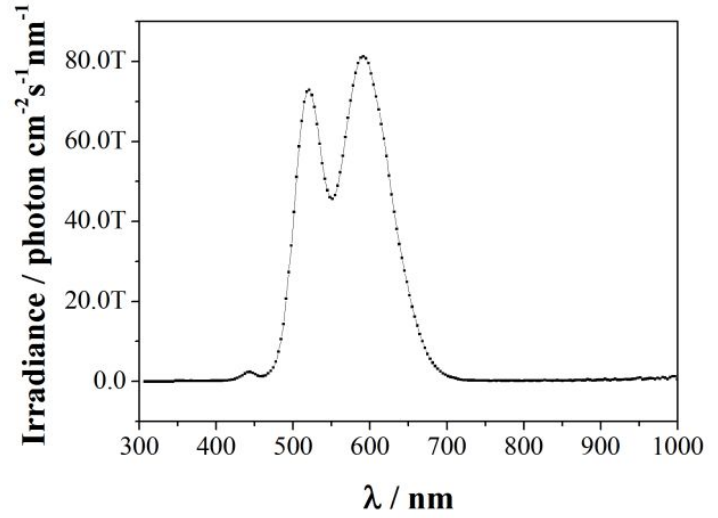

Figure S1. Irradiance spectrum of the visible light from a LED light source used in both photoelectrodeposition and charge separation efficiency measurement 


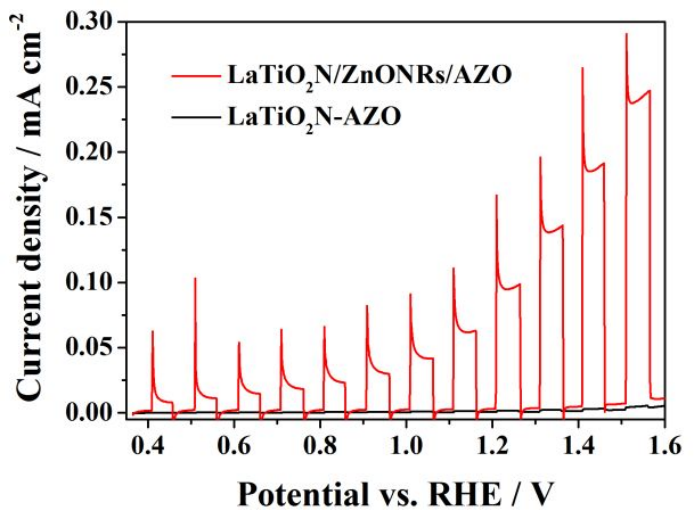

Figure S2. Current-potential characteristics of photoanodes in $0.1 \mathrm{M} \mathrm{NaOH}+0.1 \mathrm{M}$ $\mathrm{Na}_{2} \mathrm{SO}_{3}$ under chopped irradiation of the visible light from a LED light source (irradiance spectrum, Figure S1) 
(a)

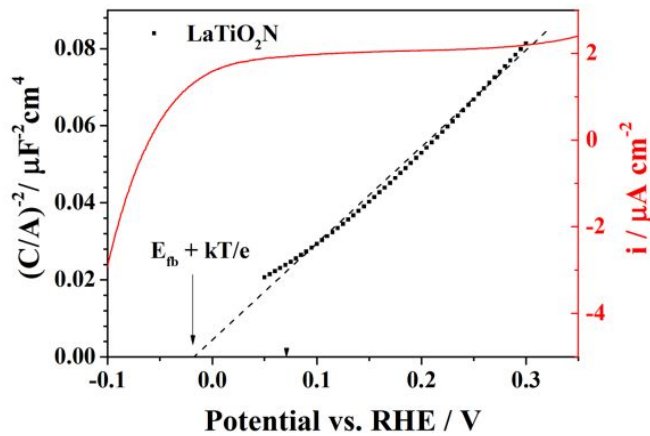

(b)

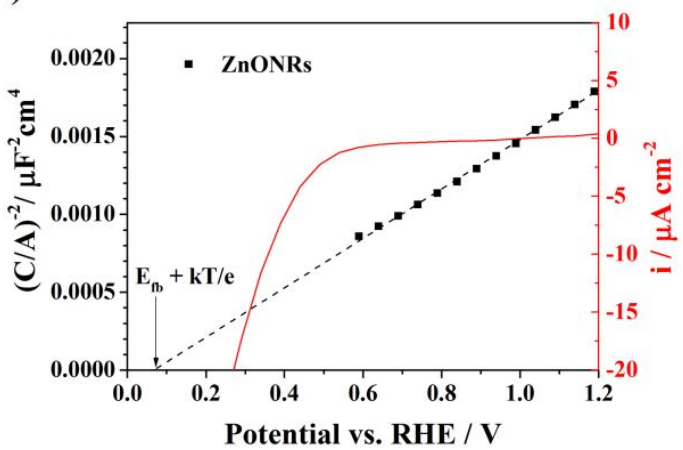

Figure S3. Mott-Schottky plots and current density-potential curves of (a) $\mathrm{LaTiO}_{2} \mathrm{~N}$ particles and (b) $\mathrm{ZnO}$ nanorods. Mott-Schottky data where the redox currents are negligible are selected to etismate $E_{f b}$ from the intercept. $k T / e=0.025 V$, so $E_{f b}\left(\operatorname{LaTiO}_{2} N\right)=-0.04$ $\mathrm{V}_{\mathrm{RHE}}, \mathrm{E}_{\mathrm{fb}}(\mathrm{ZnONRs})=0.04 \mathrm{~V}_{\mathrm{RHE}}$. 